\title{
Los conflictos de intereses de los
}

administradores y su aplicación en el manejo de la información privilegiada ${ }^{1}$

Conflict Of Interests Of Directors And Its Application In The Management Of Privileged Information

\author{
Mónica García NiÑO²
}

\section{RESUMEN}

El deber de lealtad que tiene el administrador dentro de una sociedad puede verse incumplido cuando en cabeza del administrador se radiquen dos intereses (el interés de la sociedad y un interés personal o extrasocial) que se contrapongan y este privilegie el interés extrasocial. Una de las circunstancias que puede llevar a esa contraposición de intereses se produce respecto de la información privilegiada de la sociedad y su uso indebido la cual no se protege únicamente en el derecho societario sino dada su importancia es protegida por otras áreas del derecho.

Palabras clave: deber de lealtad, conflicto de interés, información privilegiada, uso indebido de la información privilegiada.

1 Fecha de recepción: 19 de mayo de 2015. Fecha de aceptación: 25 de junio de 2015. Para citar el artículo: García, M. "Los conflictos de intereses de los administradores y su aplicación en el manejo de la información privilegiada". Revist@ E-Mercatoria, vol. 14,n.o 1, enero-junio, 2015. DOI: https://doi.org/10.18601/16923960.v14n1.05

2 Estudiante de quinto año de la Facultad de Derecho de la Universidad Externado de Colombia. Correo electrónico: monic_sg@hotmail.com. 


\section{ABSTRACT}

The duty of loyalty of the director inside a society can be violated when the director have two interests on his head (the interest of society and a personal or extrasocial interest) that oppose and he favors the extrasocial interest. One of the circumstances that may lead to the conflict of interests occurs respect of the privileged information of the society and its misuse which have protection in corporate law but given its importance is protected as well by other areas of law.

Keywords: duty of loyalty, conflict of interest, privileged information, misuse of privileged information.

\section{INTRODUCCIÓN}

En la actualidad las personas al tomar la decisión de formar una sociedad están más interesadas por los beneficios económicos que esta produce y no se centran en la administración de la misma, esto ocurre especialmente en las grandes sociedades anónimas más en las sociedades cerradas y pequeñas los socios si se interesan en la administración de la sociedad. Esta circunstancia hace necesario que deleguen esta actividad en terceros profesionales a los cuales la ley les ha asignado obligaciones y deberes específicos, además ha creado mecanismos para proteger a los socios frente a un posible incumplimiento los cuales tienen como finalidad sancionar a los administradores que actúan contrario a la ley y a la buena fe, igualmente buscan prevenir que actúen de esta manera.

La ley 222 de 1995 establece los deberes que tienen los administradores frente a la sociedad y a los socios: el deber de buena fe, el deber de diligencia y el deber de lealtad. Igualmente estableció que su actuación debe ser conforme al interés de la sociedad para lo cual debe abstenerse de participar en actos en los cuales exista conflicto de interés.

El problema de la relación administrador-sociedad se acentuó a principios del siglo XX debido a los grandes escándalos corporativos y a la amenaza que estos produjeron en la economía global lo que produjo que el derecho societario empezara a desarrollar los conflictos de interés que se producen en la relación administrador-sociedad desde los primeros años del siglo XXI. ${ }^{3}$

En este artículo se va a analizar cuál ha sido el resultado de ese desarrollo legislativo examinando los diferentes tipos de conflicto de interés haciendo énfasis en el uso indebido de la información privilegiada, partiendo del análisis 
de qué se considera información privilegiada, cuáles deben ser sus características, bajo qué circunstancias se considera que su uso fue indebido, cual ha sido su protección en otras áreas del derecho diferentes a la societaria.

La metodología empleada fue de base documental, basada en legislación colombiana, doctrina colombiana y debido a la falta de desarrollo en el país respecto de ciertos temas fue necesario utilizar el derecho comparado, especialmente la legislación española.

\section{DEBER DE LEALTAD DE LOS ADMINISTRADORES}

Los administradores le deben lealtad a la persona jurídica -sociedad- a la cual prestan sus servicios como mandatarios. ${ }^{4}$ El deber de lealtad obliga a los administradores a hacer prevalecer el interés social sobre su interés personal. En nuestro ordenamiento se encuentra establecido en el artículo 23 de la ley 222 de 1995, como uno de los tres deberes que tiene el administrador de una sociedad. ${ }^{5}$ El artículo 23 establece que los administradores deben abstenerse de participar por sí o por interpuesta persona en interés personal o de terceros en actividades que impliquen competencia con la sociedad y participar en actos respecto de los cuales exista conflicto de interés, salvo que exista una autorización expresa de la junta de socios o asamblea general de accionistas. ${ }^{6}$

En el common law el deber de lealtad "duty of loyalty" es una expresión del trust, que se refleja en la prestación de comportarse correctamente frente a la sociedad cuando los administradores detenten intereses contrarios a los de la compañía, por lo que el deber de lealtad no consiste en una obligación de

4 CÓRDOBA, Pablo Andrés. El derecho de las sociedades y el gobierno de la sociedad anónima: el interés social, órganos, accionistas y administradores. 1. ${ }^{a}$ ed., Universidad Externado de Colombia, Bogotá, 2014, p. 610. El autor considera que se debe hacer una distinción de acuerdo al tipo societario y con fundamento en sí la administración es ejercida por socios, accionistas o terceros.

5 El artículo 23 señala que los administradores deben obrar con la diligencia de un buen hombre de negocios esto es "en interés de la sociedad, y en el caso de la sociedad anónima, el interés que asiste a los accionistas". Señala el doctor Córdoba que este deber implica que "Los administradores deben controlar y supervisar la función administrativa de la compañía, estar informados y decidir conforme a los datos recibidos, debe tomar y ejecutar determinaciones razonables desde el punto de vista empresarial" Ibíd. pp. 628-629. Asimismo establece el deber de buena fe que "conlleva a las partes a comportarse de manera honesta, solidaria, leal, diligente, excluyendo cualquier situación que implique abuso del derecho o enriquecimiento sin justa causa": GAITAN, Nicolás. La Autocontratación En El Derecho De Sociedades Colombiano: Deber De Lealtad, Interés Social Y Vínculo Jurídico Administrador-Sociedad. En: Revista e-mercatoria Vol. 12, No. 2 (jul-dic. 2013).

6 Es una prohibición de carácter general para ejecutar esos actos, pero eso "no impide definitivamente la realización de tales actos, sino que somete su celebración a un riguroso procedimiento mediante el cual se pretende, en lo esencial proteger los intereses de la sociedad, sus asociados y terceros interesados" REYES VILLAMIZAR, Francisco. SAS: La Sociedad Por Acciones Simplificada. 2. ${ }^{\text {a }}$ ed. Editorial Legis. 2012. pp. 139 y 140. 
no hacer, la de evitar los conflictos de interés, sino que cuando se presente el administrador debe abstenerse de obtener un provecho propio o ajeno en caso de que se contraponga su interés con el de la sociedad. ${ }^{7}$

\subsection{CONCEPTO DE CONFLICTO DE INTERÉS ${ }^{8}$}

El conflicto de intereses es una situación de hecho ${ }^{9}$ que se presenta cuando concurren en cabeza del administrador el interés de la sociedad ${ }^{10}$ y su propio interés, en este caso el administrador se encuentra ante una situación donde hay una contraposición entre sus deberes con la sociedad y la satisfacción de su interés personal. ${ }^{11}$ Cuando se presenta esta circunstancia el administrador debe anteponer el interés de la sociedad sobre su propio interés. ${ }^{12}$

7 CÓRDOBA. Óp. cit. pp. 613 y 614.

8 Para la Superintendencia Financiera los conflictos de interés son "las situaciones de interferencia entre esferas de interés, en las cuales una persona podría aprovechar para sí o para un tercero las decisiones que él mismo tome frente a distintas alternativas de conducta en razón de la actividad misma que desarrolla y del especial conocimiento que tenga y cuya realización implicaría la omisión de sus obligaciones legales, contractuales o morales a las cuales se halla sujeto" Concepto No. 2007059749-001 del 28 de diciembre de 2007.

9 Estas situaciones son potencialmente perjudiciales para la sociedad y por ello se han ido creando distintos instrumentos normativos, de auto gobierno y/o imperativos, tendientes a conjurar los posibles efectos negativos de estas situaciones. Las reglas de prohibición tienen por objeto prohibir los conflictos de interés que el ordenamiento jurídico o la empresa juzgan objetivamente perjudiciales para la compañía, otro instrumento han sido las reglas de procedimiento que autorizan determinados conflictos siempre y cuando se satisfagan unos requisitos de procedimiento que otorguen validez a los mismos. SABOGAL. Op. cit. Página 61.

10 Sobre el concepto de interés social se han creado dos teorías: La monista o contractualista según la cual el interés social es el interés común de los socios y la dualista según la cual el interés social es más amplio e implica todos los intereses que confluyen en ella, el interés de la empresa, el de los trabajadores y el bien común el del estado. GAITAN, Op. cit. P. 18-23; CÓRDOBA. Op. cit. pp. 138-143; SERRANO CAÑAS. José Manuel. El conflicto de intereses en la administración de sociedades mercantiles, Bolonia, Publicaciones del Real Colegio de España, 2008, pp. 57-66.

11 "Quienes ejercen una función o actividad que implique tener que velar por los intereses de otro deben evitar todo conflicto entre sus intereses personales y los deberes que sus cargos imponen, lo cual se justifica en la necesidad de proteger ciertos intereses individuales, pero también el interés general". CUIF, Pierre-Francois. El conflicto de intereses: ensayo sobre la determinación de un principio jurídico en derecho privado, Revista de Derecho Privado, Nos. 12 y 13, Diciembre de 2007, Bogotá. p. 56.

12 El concepto de interés personal hace referencia a los intereses cuyo titular sea el administrador, sean de él o de terceros. Ese interés no necesariamente debe ser patrimonial, la naturaleza económica no es necesaria, basta con que exista un interés de carácter psicosocial como el prestigio, la gratitud o de carácter político, entre otros. "Es suficiente la presencia de cualquier elemento extraño al interés social, indistintamente de su naturaleza, desde que sea razonable y objetivamente apto para poner en tela de juicio la ecuanimidad e independencia de criterio del adm social". SERRANO CAÑAS. José Manuel. El conflicto 
Dentro del concepto de conflicto de interés podemos encontrar dos definiciones, el concepto restringido y el concepto amplio, las cuales difieren si el daño es o no un elemento necesario para calificar la incompatibilidad del interés del administrador respecto del interés social.

El concepto restringido hace referencia a la situación en la que concurre un riesgo absoluto, real y actual de lesión al interés societario, derivado de la concurrencia de un interés personal, de carácter pecuniario e incompatible con el interés social. El ejercicio de las funciones del administrador en conflicto es la causa fundante de un daño directo e irremediable al patrimonio social, de no ser así se validaría la conducta desleal del administrador. ${ }^{13}$

El concepto amplio, por el contrario, hace alusión a las situaciones de riesgo (hipotético o real) de infracción del deber de lealtad con el interés social. En este caso, no se restringe al interés personal y su incompatibilidad con el interés social y la presencia de un daño. Lo importante es el cumplimiento del deber de lealtad, donde el administrador debe hacer primar el interés social y anteponerlo a sus intereses personales. ${ }^{14}$ De acuerdo con la legislación colombiana es necesario que el administrador le informe a la junta de socios o asamblea de accionistas la operación que va a efectuar donde se contraponen los intereses para que esta emita su autorización.

Podemos concluir entonces que la concurrencia de intereses no significa que el administrador se encuentre violando el deber de lealtad sino que este se vulnera cuando en la contraposición de intereses el administrador realiza la operación privilegiando su interés o el interés de un tercero a él vinculado sobre el interés de la sociedad o cuando la realiza sin obtener la autorización que exige el artículo 23 de la ley 222 de 1995, debe tenerse en cuenta que así la junta de socios o la asamblea de accionistas autoricen la operación sí esta causa un daño a la sociedad el administrador debería abstenerse de realizarla.

Para el juez societario el interés que da lugar a un conflicto puede surgir por ministerio de la ley, en este caso se debe probar que un sujeto está obligado por ley a salvaguardar en forma simultánea intereses de las dos sociedades que participan en la operación. También puede presentarse el conflicto cuando el administrador tiene un interés económico que sea lo suficientemente significativo como para menoscabar su capacidad de cumplir con las funciones propias del cargo. Igualmente hay conflicto de interés cuando además de un lazo afectivo fuerte entre el administrador y un pariente o cuando hay un interés económico derivado de la vocación sucesoral del administrador. ${ }^{15}$

de intereses en la administración de sociedades mercantiles, Bolonia, Publicaciones del Real Colegio de España, 2008, p. 71.

Ibíd. pp. 78-79.

Ibíd. pp. 78-79.

Sentencia Superintendencia de Sociedades. Partes: Sucesión de María del Pilar Luque Schaefer contar Luque Torres Ltda. En liquidación. p. 7. 


\subsection{Tipología DEL CONFLiCTO DE INTERESES}

El conflicto de intereses se puede presentar en diferentes situaciones ${ }^{16}$ dentro de estas encontramos la auto contratación, la participación de los administradores en la fijación de su remuneración, la indebida utilización de información privilegiada y la competencia de los administradores, en este acápite vamos a explicar desde un punto de vista general cada una para poder centrarnos posteriormente en la indebida utilización de información privilegiada que es el objeto de la investigación.

\subsubsection{Auto-contratacion: contratos del administrador con la sociedad}

Se presenta cuando el administrador celebra un contrato con la sociedad, donde concurre en cabeza del administrador su interés y el de la sociedad, sin embargo esta situación no necesariamente implica un conflicto de interés debido a que un elemento esencial para que exista conflicto de interés es la incompatibilidad de los intereses que concurren en cabeza del administrador, pero puede que el contrato que se va a celebrar no perjudique a la sociedad y por el contrario produzca un beneficio tanto para el administrador como para la sociedad por lo que en este caso la sociedad no se vería afectada, ni habría un riesgo de lesionar el interés social. Lo contrario ocurriría si al celebrar el contrato la sociedad sufriera algún perjuicio.

La autocontratación se ha considerado como un conflicto de interés ya que no hay proceso de negociación, por lo que el administrador que se encuentre frente a esta situación debe comunicarla al máximo órgano social para que éste autorice o no la operación. De no comunicarla y celebrar el contrato sin la autorización el administrador estaría violando el deber de lealtad consagrado en el artículo 23 de la ley 222 de 1995 o cuando el administrador comunica a la asamblea de accionistas o a la junta de socios y le dan la autorización pero privilegia su interés propio o el de un tercero a expensas del interés de la sociedad de conformidad con el decreto 1925 de $2009 .{ }^{17}$

16 "En algunos sistemas las reglas se basan en la aplicación de pautas especiales de fiscalización judicial, diseñadas para establecer si una operación controvertida se celebró bajo condiciones de mercado" Sentencia Superintendencia de Sociedades. Partes: SAC Estructuras Metálicas S.A. contra Praxedis José Daniel Correa Senior, Santiago Francisco Correa Laverde y Gloria Estella Gallo Pérez. p. 4.

CÓRDOBA. Op. cit. p. 628. 


\subsection{Fijación de la remuneración de los administradores}

Este conflicto se presenta cuando los administradores tienen la potestad de determinar su propia remuneración. Este problema es mayor cuando hay una división entre gobierno de la sociedad, y la propiedad de las acciones. ${ }^{18}$ En las sociedades donde no se presenta la mencionada división el conflicto se minimiza, ya que es menos posible que los administradores se desvíen del interés social causando un perjuicio a la sociedadi o será más fácil de resolver, bien sea a través de los estatutos o por determinación de la asamblea general de accionistas o junta de socios. ${ }^{19}$

El órgano competente para determinar la remuneración de los administradores por regla general es el máximo órgano social, es decir la asamblea general o la junta de socios, excepto que por alguna estipulación se establezca expresamente que esta función es asignada a otro órgano. ${ }^{20}$ Se puede deducir del art 185 del código de comercio que en principio los administradores si son accionistas no tienen inconveniente en fijarse en sede de asamblea general o junta de socios el monto de su remuneración pero debe haber una relación entre el servicio que presta a la sociedad, su experiencia profesional y los beneficios que recibe la sociedad, de lo contrario se puede ver afectado el interés social y se podrían impugnar las decisiones por las cuales se fijó la remuneración dentro del término y la vía establecida en el ordenamiento jurídico colombiano. ${ }^{21}$

\subsection{Competencia de los administradores con la sociedad}

El articulo 23 en su numeral $7^{\circ}$ de la ley 222 de 1995 establece que los administradores deben abstenerse de participar en actividades que impliquen competencia con la sociedad o en actos respecto de los cuales exista conflicto de interés, salvo autorización expresa del máximo órgano social. ${ }^{22}$ Por lo que

18 Debido a que "se presentan problemas que muy probablemente no se solucionan estatutariamente desde la constitución de la sociedad, toda vez que es imposible que se prevean todas las hipótesis, en especial las referidas al mercado de los managers. Es poco pragmático pensar que en una anónima inscrita o de gran tamaño se estén cambiando continuamente los estatutos sociales para fijar las políticas o parámetros generales relacionados con la remuneración de los administradores" Ibíd. p. 640.

19 Ibíd. p. 639

20 Así lo dispone, entre otras normas, el artículo 420 del Código de Comercio.

21 CÓRDOBA. Op. cit. pp. 640 y 641.

22 Este articulo tiene como antecedente el artículo 6 de la ley 155 de 1959. El cual establecía que los Presidentes, Gerentes, Directores, representantes legales, Administradores o miembros de Juntas Directivas de empresas constituidas como sociedades anónimas no podían distribuir por si ni por interpuesta persona los productos o servicios producidos por la respectiva empresa, ni ser socios de empresas comerciales, que distribuyan o vendan principalmente tales productos, mercancías, artículos o servicios. 
se podría pensar que son dos actos diferentes a través de los cuales se viola el deber de lealtad del administrador con la sociedad, pero no debe entenderse así ya que tienen las mismas consecuencias la competencia del administrador con la sociedad como los demás conflictos de intereses y para poder realizarse la competencia con la sociedad es necesario que haya autorización por parte de la Junta de socios o Asamblea de accionistas. Se pueden diferenciar en que el conflicto de intereses per se no implica una violación al deber de lealtad en cambio cuando el administrador está en competencia con la sociedad sin la autorización y hay un detrimento del interés social el administrador está violando el deber de lealtad. ${ }^{23}$

De acuerdo a la circular externa de la superintendencia de sociedades 006 de 2008 los actos de competencia son los que implican una concurrencia entre el ente societario y el administrador cuando cada uno de ellos persigue la obtención de un mismo resultado. Como ocurre cuando pretenden la adquisición de unos productos o servicios, o el posicionamiento en un mercado al que ambos concurren.

La superintendencia igualmente considera que la disposición legal les prohíbe a los administradores que participen en actividades que impliquen competencia con la sociedad, sin calificar la forma como se desarrolle esa competencia, si es desleal o si es completamente licita, lo que tiene relevancia respecto de estos actos es el hecho de competir. Por lo que el administrador no puede argumentar que los actos de competencia no tienen calificativo de desleales. ${ }^{24}$

Entonces los actos de competencia suceden al inicial conflicto de intereses que per sé no significa la transgresión del deber de lealtad, lo cual indica que cuando un administrador realiza uno o varios actos de competencia con la sociedad no sólo existe conflicto de intereses sino que se aprovechó de éste para obtener un beneficio a expensas de la compañía. El conflicto antecede al acto de competencia en sí y por ello son diferentes desde una perspectiva temporal, pero igualmente son distintos en que el primero no constituye por sí sólo una violación al deber de lealtad, mientras que el segundo lo es cuando no se ha obtenido la autorización del máximo órgano o se logró en detrimento del interés social.

Para que exista el acto de competencia debe ser efectivo, por lo que puede que se tenga el mismo objeto social, pero si no se encuentra en el mismo mercado no existe conflicto de intereses y menos un acto de competencia que implique la violación del deber de lealtad. Si un administrador ejerce su cargo en dos o más sociedades de igual o similar objeto social esto no implica per pectiva temporal, ya que el conflicto antecede al acto de competencia en sí, ya que el administrador inicialmente se encuentra en un conflicto de intereses, pero al comenzar a competir con la compañía se aprovecha de este para obtener un beneficio.

24 ALMONACID SIERRA, Juan Jorge. Derecho de la Competencia, Legis, 1998. p. 274. 
se y no es suficiente para considerar que existe un acto de competencia por parte del administrador si las sociedades se ubican en mercados distintos. ${ }^{25}$

Puede considerarse que una aplicación del deber de no competencia es el no aprovechamiento de oportunidades de la sociedad por parte de los administradores, los cuales tienen el derecho de libre iniciativa privada y de actividad económica propia consagrados en la Constitución pero debido al deber de lealtad se ven limitados, por lo que se obligan a una prestación de no hacer, que es no aprovecharse de las oportunidades de negocio de la compañía de las cuales han tenido conocimiento en razón de su cargo en la sociedad. ${ }^{26}$

Esta limitación no es absoluta ya que pueden haber situaciones en las que el administrador compite con la sociedad sin vulnerar el deber de lealtad, un ejemplo de esto es cuando la sociedad no tiene la capacidad financiera para aprovecharla, no tiene la capacidad legal, o cuando por la demora de las autorizaciones necesarias no se aprovecha por las características del negocio que no dan margen de espera. ${ }^{27}$

\subsection{Autorización de la asamblea de accionistas o junta de socios}

Hay algo transversal a todas las hipótesis de conflictos de intereses de acuerdo al parágrafo del artículo 23 de la ley 222 de 1996 y al artículo segundo del decreto 1925 de 2009. En caso de conflicto de interés el administrador debe ordenar la convocatoria o debe convocar a la Asamblea General o Junta de Socios señalando dentro del orden del día la solicitud de autorización para la actividad que le representa el conflicto. Durante la reunión el administrador debe suministrar toda la información relevante para la toma de decisión y en la decisión debe excluirse su voto en caso de que sea socio. Se debe tener de presente que la autorización debe ser previa y expresa y no puede otorgarse cuando el acto perjudique los intereses de la sociedad ${ }^{28}$ por lo que al dar la autorización se deben tener en cuenta criterios objetivos y la autorización se puede otorgar teniendo en cuenta que se va a causar un perjuicio a la sociedad pero que es un daño temporal porque la sociedad posteriormente va a obtener un mayor beneficio. ${ }^{29}$

CÓRDOBA. Op. cit. p. 654.

Ibíd. pp. 654-655.

Ibíd. p. 656.

Si los socios autorizan la realización de un acto en el cual exista conflicto de intereses y se perjudique el interés de la sociedad serán responsables solidaria e ilimitadamente por los perjuicios que se ocasionen, salvo que se haya obtenido la autorización de manera engañosa. Además conlleva la declaratoria de nulidad de los actos que hayan sido realizados como consecuencia de la autorización. Lo anterior de acuerdo al artículo cuarto del Decreto 1925 de 2009.

CÓRDOBA. Op. cit. p. 657. 
En caso de que sea otorgada la autorización y se perjudique a la sociedad el administrador no debería acatarla ya que el administrador debe hacer primar el interés social sobre cualquier otro interés y si se causa un perjuicio debe responder. Si el administrador obtiene la autorización porque brindo información incompleta o falsa no puede ampararse en la autorización para exonerarse de responsabilidad por sus actos y en consecuencia debe responder frente a la sociedad, los socios o terceros perjudicados ${ }^{30}$.

Si no se solicita la autorización el administrador se habrá comportado de manera desleal y responderá por los daños que haya ocasionado con su conducta. ${ }^{31}$ De acuerdo a la doctrina además tiene como consecuencia la nulidad de las operaciones concernientes, tema que se va a explicar a continuación.

\subsection{Consecuencias Del incumplimiento}

De acuerdo a la Ley 222 de 1996 y al Decreto 1925 de 2009 las consecuencias del incumplimiento de lo previsto en el numeral 7 del artículo 23 de la ley 222 de 1996 son la nulidad absoluta del respectivo negocio jurídico celebrado en contraposición de ese deber y la responsabilidad solidaria e ilimitada de los administradores por los perjuicios que por dolo o culpa se ocasionen a los asociados, a la sociedad o a terceros perjudicados. Además el administrador puede ser sancionado con multas y/o con la inhabilidad para ejercer el comercio, sin perjuicio de la responsabilidad penal que dicha conducta pudiese generar.

De acuerdo al artículo 5 del Decreto 1925 de 2009 el proceso judicial para obtener la declaratoria de nulidad absoluta de los actos ejecutados en contra de los deberes del administrador del numeral $7^{\circ}$ del artículo 23 , se adelantara mediante el proceso verbal sumario excepto que se haya sometido esta situación a pacto arbitral o amigable composición. El trámite de la nulidad se puede surtir en sede administrativa o judicial, pero la nulidad es saneable por la ratificación del máximo órgano social. ${ }^{32}$

Declarada la nulidad se deben restituir las cosas a su estado anterior, salvo los derechos de terceros que hayan obrado con buena fe, lo que podría tener como consecuencia que se tengan que reintegrar ganancias obtenidas con la realización de la conducta sancionada. Sin perjuicio de las acciones de impugnación de las decisiones que están consagradas en el artículo 191 y siguientes del código de comercio. En caso de las SAS se aplicara el artículo 44 de la ley 1258 de 2008.

30 De acuerdo al Artículo tercero del Decreto 1925 de 2009

31 GAITAN, Nicolás. Op. cit. pp. 14-15.

32 Sentencia Superintendencia de Sociedades. Partes: SAC Estructuras Metálicas S.A. contra Praxedis José Daniel Correa Senior, Santiago Francisco Correa Laverde y Gloria Estella Gallo Pérez. pp. 5 y 6. 
Respecto de la responsabilidad patrimonial de los administradores de acuerdo al artículo 24 de la ley 222 de 1995 el cual modifico el artículo 200 del código de comercio, los administradores responden solidaria e ilimitadamente de los perjuicios que por dolo o culpa ocasionen a la sociedad, a los socios o a terceros. Y en los casos de incumplimiento o extralimitación de funciones, violación de la ley o de los estatutos se presume la culpa del administrador.

Adicionalmente la sociedad está facultada para obtener la indemnización de los perjuicios que le hubiesen sido causados por el administrador mediante la acción de responsabilidad social contra los administradores. ${ }^{33}$

\section{INDEBIDA UTILIZACIÓN DE INFORMACIÓN PRIVILEGIADA}

El administrador tiene un deber de confidencialidad respecto de uno de los activos más importantes de las sociedades en la actualidad, la información. El numeral 5 del artículo 23 de la ley 222 de 1995 establece que el administrador en cumplimiento de su función debe abstenerse de utilizar indebidamente información privilegiada. Respetando el deber de lealtad los administradores deben tener una buena utilización de la información, ya que de no ser así la información pierde valor y perjudica el interés social.

Para poder comprender esta situación de conflicto es necesario hacer un estudio más profundo de la información analizando que se entiende por información privilegiada y en que eventos hay un uso indebido de esta.

\subsection{La Informacion de La Sociedad}

Actualmente la información no se ve como algo accesorio y sometido al capital y al trabajo sino que es un sistema de creación y acumulación de riqueza, ahora el medio de producción es el conocimiento, la información aplicada a la productividad. Por lo que en el mundo actual de los negocios el privilegio es contar con información veraz, la cual es un bien comercializable y su valor es proporcional a la utilidad que reporte al que cuenta con ella. ${ }^{34}$

Podemos afirmar que la información de la sociedad está vinculada con la sociedad sin que importe la fuente de donde la obtuvo el administrador o si está incorporada o no en un soporte físico. Dentro de esta información se incluyen las proyecciones, lo que se planea hacer y también la información de operaciones anteriores, de actividades y negocios que se hicieron, tuvieran o no un resultado positivo o el esperado para la sociedad. En este orden, debe 
siempre examinarse si la información se relaciona con el objeto social para determinar si es información de la sociedad.

En legislaciones como la española se ha tratado como un deber separado del de lealtad, denominándolo el deber de secreto, donde se impone al administrador el deber de guardar secreto de las informaciones de carácter confidencial, las informaciones, datos, informes o antecedentes que conozcan como consecuencia del ejercicio del cargo, sin que las mismas puedan ser comunicadas a terceros o ser objeto de divulgación cuando pudieran tener consecuencias perjudiciales para el interés social, este deber lo tiene el administrador incluso después de cesar sus funciones. ${ }^{35}$

En el sistema legal estadounidense se sanciona como una violación del deber fiduciario de lealtad, la utilización indebida de la información privilegiada por parte del administrador sobre información que conoce en ejercicio de su funciones pero que no es de dominio público, y el acceso a ella es temporal o permanentemente restringido, donde es evidente que la sociedad ha adoptado medios para evitar que terceros conozcan algunos detalles de su funcionamiento o desarrollo, y si se le permitiera su uso discrecional se podrían ver perjudicados los intereses de una compañía y de sus asociados. Y los administradores no deben tener la posibilidad de lucrase injustificadamente mediante el uso indebido de la información. ${ }^{36}$

El uso indebido de la información interna de la sociedad con base en la cual se realizan transacciones denominadas "insider traiding" ${ }^{\text {"37 }}$ genera responsabilidad para quien la realiza cuando se cumplen los siguientes supuestos: ${ }^{38}$

La existencia de una relación que permita obtener información confidencial e interna de la sociedad, que deba servir para beneficio exclusivo de esta.

La injusticia de que quien posee la información obtenga un beneficio personal, mediante la realización de la transacción sin poner en conocimiento del publico la información o generando confusión con respecto de la real situación de la sociedad.

Inicialmente no se vio como una violación a los deberes por parte del administrador, posteriormente se utilizó la teoría de los hechos especiales, la cual permite hacerlo cuando especiales circunstancias así lo justifican, finalmente

SANCHEZ, Op. cit. p. 212.

REYES VILLAMIZAR, Francisco. Derecho Societario en los Estados Unidos: introducción comparada. Segunda Edición, Editorial legis, Bogotá, 2005. p. 78.

37 En la jurisprudencia norteamericana y en las regulaciones de la SEC (Security Exchange Commission) se ha denominado los casos en los que el administrador realiza operaciones, con base en la información conocida por él, la cual incide en el valor de la acción, bien sea incrementándola o disminuyéndola. BARRIENTOS, RESTREPO, Ana Lucia. Administradores, información confidencial y propiedad accionaria. En: Revista de Derecho y ciencias políticas, edición universidad pontificia bolivariana, No 99, 1998, Medellín. p. 145 .

Ibíd. pp. 145-146. 
se estableció la regla de la minoría, según la cual el director tiene el deber con los accionistas de divulgar la información. Para prevenir el insider trading es necesario reducir la existencia de información privilegiada. ${ }^{39}$

\subsection{LA INFORMACION PRIVILEGIADA}

\subsubsection{Definición}

La información privilegiada es el "conjunto de datos que sirve de materia prima para tomar decisiones razonables, que tiene carácter societario, que es confidencial, es decir que no puede darse a conocer indiscriminadamente, y que conlleva un interés digno de tutela jurídica por mantenerla en reserva". ${ }^{40}$

El Dr. Carlos Mario Giraldo toma la definición de la ley española según la cual información privilegiada es "aquella información con carácter concreto que no ba sido dada a conocer al público y que de baberlo sido babría tenido en cuenta un inversionista medianamente diligente y prudente al negociar los respectivos valores". ${ }^{41}$

De acuerdo al Dr. Luis Suarez cuando explica los diferentes conceptos al explicar la conducta penal establece que la información privilegiada "es aquella a la cual solo tiene acceso directo determinadas personas por razón de su profesión u oficio, la que está sometida a reserva, pues si se da a conocer permitiría ser utilizada en perjuicio de su titular". ${ }^{42}$

Para poder determinar si la información de un comerciante es confidencial es necesario que esté compuesta por datos de vital importancia para "conservar la autonomía y la iniciativa individual en materia económica de la sociedad" y debe permitir mantener la "viabilidad de la actividad económica de la empresa". ${ }^{43}$

La Circular 006 de 2008 de la superintendencia de sociedades define la información privilegiada como aquella a la cual solo tienen acceso ciertas personas, como los administradores, en razón de su profesión u oficio, la cual por su carácter está sujeta a reserva, ya que de conocerse podría ser utilizada con el fin de obtener provecho o beneficio para sí o para un tercero.

39 DOBSON, Juan I. Interés societario. Ed. Astrea, Argentina, 2010. pp. 167-169.

40 CÓRDOBA. Op. cit. p. 648.

41 GIRALDO MORENO, Carlos. La Información Privilegiada de la Empresa su Tratamiento en Colombia y en el Derecho Comercial Comparado, EN: La Contratación Mercantil y otros aspectos comerciales, Colegio abogados de Medellín, biblioteca jurídica Dike. p. 245.

42 SÚAREZ, Alberto. Delitos contra el Patrimonio Económico, Universidad Externado de Colombia, 2013. p. 463.

43 ALMONACID SIERRA. Op. cit. pp. 329 y 330. 
Para efectos de la investigación se entenderá como sinónimos información confidencial ${ }^{44}$, información reservada ${ }^{45}$ e información privilegiada ${ }^{46}$, entendidos como aquella información a la que se ha tenido acceso debido al desempeño de un cargo o el ejercicio de una función ${ }^{47}$ y que por su relevancia no puede ser utilizada sino de acuerdo al interés de su propietario y el uso de esta en provecho propio o de un tercero que le genere un perjuicio a la sociedad y haga que la información pierda su valor tiene consecuencias jurídicas ya que esta información está protegida por nuestro ordenamiento jurídico.

\subsubsection{Características}

Presentada la definición y sus alcances, conviene ahora revisar las principales características que debe tener la información para ser calificada como privilegiada:

\subsubsection{Utilidad de la información ${ }^{48}$}

La información no necesariamente debe ser novedosa sino que debe tener una utilidad para que al administrador se le pueda exigir reserva. Si la información puede ser conocida por cualquier persona sin que sea necesario que tenga la calidad de administrador, si el público puede acceder a ellas sin que existan barreras para su obtención, esta información puede ser societaria pero no privilegiada ${ }^{49}$ Debe tener la idoneidad suficiente para ser utilizada y además debe versar sobre hechos concretos y referidos al entorno societario o al ámbito dentro del cual actúa la compañía. ${ }^{50}$

44 De acuerdo al Diccionario de la Real Academia de la Lengua Española confidencial es aquella noticia que está reservada.

45 De acuerdo al Diccionario de la Real Academia de la Lengua Española reserva es la guarda o custodia que se hace de algo.

46 De acuerdo al Diccionario de la Real Academia de la Lengua Española es aquella que por referirse a hechos o circunstancias que otros desconocen puede generar ventajas a quien dispone de ella.

47 Si la información proviene de otra fuente y no como consecuencia del ejercicio del cargo y sin conexión a este o no se refiere a la sociedad no será confidencial. SANCHEZ CALERO, Fernando. Los administradores en las sociedades de capital. Segunda edición, Thomson-civitas, 2007. p. 214.

48 De acuerdo a la Circular Externa No. 6 de 2008 la información debe tener la idoneidad suficiente para ser utilizada y versar sobre hechos concretos y referidos al entorno societario o al ámbito dentro del cual actúa la compañía.

49 CÓRDOBA. Op. cit. pp. 649-650.

50 Superintendencia de Sociedades Circular Externa 006 de 2008. 


\subsubsection{Interés legítimo en la confidencialidad de la información}

La sociedad puede verse perjudicada ${ }^{51}$ si la información es conocida, sea porque "se priva de una ventaja competitiva que la información divulgada le reportaba, o simplemente por verse expuesta a surgir un perjuicio solo por el becho de baberse difundido los datos constitutivos de la información". 52

\subsection{USO INDEBIDO DE LA INFORMACION PRIVILEGIADA}

De acuerdo a la circular externa de la superintendencia de sociedades No. 6 de 2008 se considera que hay un uso indebido de la información privilegiada cuando quien la posee y está en la obligación de mantenerla en reserva incurra en cualquiera de las siguientes conductas, independientemente de que su actuación le reporte o no beneficios:

a. Que se suministre a quienes no tienen derecho a acceder a ella. Caso en el cual el uso seria indebido ya que la información fue suministrada a quien no tenía derecho para recibirla.

b. Que se use con el fin de obtener provecho propio o de terceros.

c. Que la oculte maliciosamente en perjuicio de la sociedad o en beneficio propio o de terceros, lo cual supone usarla solo para sí y, por abstención, en perjuicio de la sociedad para estimular beneficio propio o de terceros.

d. Cuando existiendo la obligación de darla a conocer no se haga pública y se divulgue en un medio cerrado o no se divulgue de manera alguna.

Para poder hacer uso de esa información de la sociedad, en caso de conflicto de interés es necesario obtener la autorización de la asamblea general de accionistas, de acuerdo a lo dispuesto en el numeral $7^{\circ}$ del artículo 23 de la ley 222 de 1995 . No se debe autorizar el uso de esa información cuando va contra los intereses de la sociedad. ${ }^{53}$

De acuerdo a la circular externa No. 6 de 2008 en los siguientes casos no se configura uso indebido de la información privilegiada:

a. Cuando el órgano competente de la sociedad autorice expresamente al administrador el levantamiento de la reserva.

b. Cuando la información se le suministre a las autoridades facultadas para solicitarla y previa su solicitud.

c. Cuando es puesta a disposición de los órganos que tienen derecho a conocerla, como la asamblea general de accionistas, la junta directiva, el revisor fiscal, los asociados en ejercicio del derecho de inspección y los asesores

51 Si en su divulgación no causa consecuencias perjudiciales a la sociedad, el administrador no tiene ese deber de confidencialidad. SANCHEZ, Op. cit. p. 214.

52 CÓRDOBA. Op. cit. p. 650.

53 CÓRDOBA, Op. cit. p. 651. 
externos, etc. Teniendo en cuenta la limitación establecida en el artículo 48 de la ley 222 de $1995 .{ }^{54}$

\subsection{LA PROTECCIÓN DE LA INFORMACIÓN PRIVILEGIADA EN OTRAS ÁREAS DEL DERECHO}

\subsubsection{En el derecho de la propiedad industrial}

En el derecho de la propiedad industrial la información privilegiada de la sociedad es protegida mediante el denominado "secreto ${ }^{55}$ empresarial", el cual es definido por la Decisión 486 del 2000 de la Comunidad Andina como cualquier información no divulgada que una persona natural o jurídica legítimamente posea, que pueda usarse en alguna actividad productiva, industrial o comercial y que sea susceptible de transmitirse a un tercero. Esa información de acuerdo a la Decisión 486 y al artículo 39.2 ADPIC debe ser secreta ${ }^{56}$, debe tener un valor comercial por ser secreta ${ }^{57}$ y haber sido objeto de medidas razonables tomadas por su legítimo poseedor para mantenerla secreta.

El secreto empresarial está constituido por información empresarial aquella que recae sobre materias concernientes a la empresa y a su actividad, productos, ideas procedimientos o experiencias industriales o comerciales. Por lo que el objeto del secreto pueden ser invenciones patentables o no patentables, dibujos, modelos industriales técnicas de venta, planes financieros, relaciones de clientes o proveedores. No es únicamente la información inherente al sector industrial o técnico de la empresa sino todo lo relacionado a la empresa, aspectos de su organización interna, relaciones, estrategias, entre otros. ${ }^{58}$

54 Establece que el derecho de inspección de los asociados no se extiende a los documentos que versen sobre secretos industriales o cuando se trate de datos que de ser divulgados, puedan ser utilizados en detrimento de la sociedad.

55 El Diccionario de la Real Academia de la Lengua lo define como: "cosa que cuidadosamente se tiene reservada y oculta ${ }_{i}$ Conocimiento que exclusivamente alguien posee de la virtud o propiedades de una cosa o de un procedimiento útil en medicina o en otra ciencia, arte u oficio."

56 La decisión 486 establece que es secreta porque no es generalmente conocida, ni fácilmente accesible por quienes se encuentran en los círculos que normalmente manejan la información respectiva.

La información secreta es aquella que "solo puede ser conocida por sus titular legítimo y por aquellas personas vinculadas a él por relaciones comerciales o laborales en las que media un acuerdo de confidencialidad." CASTRO GARCÍA, Juan David. La Propiedad Industrial, Universidad Externado de Colombia, 2009. pp. 429-430.

57 El valor comercial se deriva de que dicha información sea mantenida secreta y que permita mejorar la competitividad dentro del mercado a quien la posee. Ibíd. p. 430.

58 GALAN CORONA, Eduardo, Tipos de deslealtad en materia de secretos empresariales EN: Estudios de derecho mercantil en homenaje al profesor José María Muñoz Planas. 2011. pp. 236 y 237. 
El secreto empresarial es protegido por la decisión 486 en su Artículo 265, el cual establece quien tiene acceso al secreto empresarial debido a su trabajo o relación de negocios debe abstenerse de usarlo, divulgarlo, revelarlo sin causa justificada y sin consentimiento de la persona que posea el secreto.

La doctrina ha establecido criterios para saber cuándo la información es divulgada ${ }^{59}$ :

a. Responde al factor cuantitativo: hay divulgación cuando es conocido el secreto por un número amplio de personas.

b. Responde al factor cualitativo: hay divulgación cuando es conocido por la mayoría de los interesados, los competidores del poseedor del secreto.

El acuerdo ADPIC ${ }^{60}$ constituye el primer acuerdo internacional que regula en su sección 7 la protección de la información no divulgada. El artículo 39.1 establece que "Al garantizar una protección eficaz contra la competencia desleal, de conformidad con lo establecido en el artículo 10bis del Convenio de París (1967), los Miembros protegerán la información no divulgada de conformidad con el párrafo 2, y los datos que se hayan sometido a los gobiernos o a organismos oficiales, de conformidad con el párrafo 3." Igualmente establece que para impedir que la información se divulgue, sea adquirida o utilizada por terceros sin su consentimiento de manera contraria a los usos comerciales, ${ }^{61}$ la información debe ser secreta, debe tener un valor comercial por ser secreta y debe haber sido objeto de medidas razonables para mantenerla secreta tomadas por la persona que legítimamente la controla.

El régimen de propiedad industrial no fija un término de protección por lo que existe durante todo el tiempo que el titular de la información la mantenga secreta y continúe teniendo valor comercial. ${ }^{62}$

\subsubsection{En el derecho de la competencia}

La violación de secretos empresariales constituye un supuesto de competencia desleal ya que afecta el correcto funcionamiento del mercado porque al apro-

59 RAMIREZ, Mónica. COMPETENCIA DESLEAL por violación al secreto empresarial, tesis de grado, Bogotá D.C Colombia 2001. p. 61.

60 Acuerdo sobre Derechos de Propiedad Intelectual Relacionados con el Comercio, suscrito entre la OMC (Organización Mundial del Comercio) y la OMPI (Organización Mundial de la Propiedad Intelectual). Que corresponde al Anexo 1C del tratado constitutivo de la organización mundial del comercio.

61 De acuerdo al ADPIC, se entiende que la expresión "de manera contraria a los usos comerciales honestos" significa por lo menos las prácticas como el incumplimiento de contratos, el abuso de confianza, la instigación a la infracción, e incluye la adquisición de información no divulgada por terceros que supieran, o que no supieran por negligencia grave que la adquisición implicaba tales prácticas. ADPIC, pie de página \#10.

62 CASTRO GARCÍA, Juan David. La Propiedad Industrial, Universidad Externado de Colombia, 2009. p. 434. 
piarse de secretos empresariales permite una mejora en la posición competitiva en el mercado que no se debe a su propio esfuerzo sino al haberse apropiado del secreto. No solo se protege al competidor que se vio afectado sino también el interés general debido a que se protege el funcionamiento del mercado ya que su protección conlleva a la creación de nueva información para que sea protegida y así haya innovación en el mercado. ${ }^{63}$

La ley 256 de 1996 protege el secreto empresarial, considerando desleal la violación de estos en su artículo 16:

ARTÍCULO 16. VIOLACIÓN DE SECRETOS. Se considera desleal la divulgación o explotación, sin autorización de su titular, de secretos industriales o de cualduiera otra clase de secretos empresariales a los que se baya tenido acceso legítimamente pero con deber de reserva, o ilegítimamente, a consecuencia de algunas de las conductas previstas en el inciso signiente o en el artículo 18 de esta ley.

Tendrá así mismo la consideración de desleal, la adquisición de secretos por medio de espionaje o procedimientos análogos, sin perjuicio de las sanciones que otras normas establezcan.

Para que se configure esta conducta catalogada como un supuesto de competencia desleal se requiere la divulgación o explotación de secretos empresariales a los que se tenga acceso legítimamente pero con deber de reserva o ilegítimamente sin autorización de su titular u obteniendo la información mediante espionaje o procedimientos similares. Los secretos empresariales recaen sobre listas de clientes, catálogos de precios, lista de proveedores de materias primas, análisis de métodos de trabajo, etc. ${ }^{64}$

La Decisión Andina 486 del 2000 en su artículo 262 hace una clasificación de los diferentes actos de competencia desleal respecto del secreto empresarial estableciendo las siguientes conductas:

a) explotar, sin autorización de su poseedor legítimo, un secreto empresarial al que se ha tenido acceso con sujeción a una obligación de reserva resultante de una relación contractual o laboral

b) comunicar o divulgar, sin autorización de su poseedor legítimo, el secreto empresarial referido en el inciso a) con ánimo de obtener provecho propio o de un tercero o de perjudicar a dicho poseedor;

c) adquirir un secreto empresarial por medios ilícitos o contrarios a los usos comerciales honestos;

d) explotar, comunicar o divulgar un secreto empresarial que se ha adquirido por los medios referidos en el inciso c);

e) explotar un secreto empresarial que se ha obtenido de otra persona sabiendo, o debiendo saber, que la persona que lo comunicó adquirió el secreto 
por los medios referidos en el inciso c), o que no tenía autorización de su poseedor legítimo para comunicarlo;

f) comunicar o divulgar el secreto empresarial obtenido conforme al inciso e), en provecho propio o de un tercero, o para perjudicar al poseedor legítimo del secreto empresarial ${ }_{i}$

Además para la protección de la información privilegiada se han usado figuras como las cláusulas de no competencia las cuales son acuerdos entre dos o más empresas o personas, con el fin de evitar que una o más de ellas participe en el futuro en una determinada actividad económica y dispute la clientela en el mercado, de acuerdo a lo dispuesto por el artículo 19 de la ley 155 de 1959 y el articulo 46 del decreto 2153 de 1992 los acuerdos, convenios, operaciones y conductas contrarios a la libre competencia adolecen de objeto ilícito.

En Colombia las prácticas restrictivas de la competencia se analizan bajo dos regímenes diferentes: la regla per $s e^{65}$ y la regla de la razón. ${ }^{66}$ Para analizar si una cláusula de no competencia es o no anticompetitiva se debe mirar si el objetivo principal del contrato o acuerdo es impedir la competencia y en este caso estaríamos ante una conducta per se ilegal. Pero si es accesorio al contrato cuyo objeto no es anticompetitivo el acuerdo no sería ilegal ya que la ley no define como ilegal u acuerdo orientado a abstenerse temporalmente de prestar un servicio que se incluye como una obligación accesoria para el cumplimiento del objetivo principal del contrato al cual pertenece por lo que este tipo de cláusulas que son accesorias deben analizarse a través de la regla de la razón. ${ }^{67}$

La SIC estableció en la Resolución 46325 de 2010 el test que se utiliza para estudiar las cláusulas de no competencia y definir si son legales o no. Estableciendo 3 condiciones para que sean legales: que sean accesorias, deben buscar la realización y efectiva ejecución de otra obligación y no deben impedir el acceso de terceros al mercado.

\subsubsection{En el derecho penal}

La información como objeto autónomo de protección refleja su valor en el ámbito económico como en el de poder. Es un bien intangible dentro de toda

65 De acuerdo a esta regla la sola comisión de la conducta, ya sea un acto o un acuerdo contrario a la libre competencia, configura una violación a la ley. No es necesario ver la voluntad de las partes ni los efectos anticompetitivos. Las cuales deben estar expresamente señaladas en la ley.

66 Las conductas que no están expresamente prohibidas deben ser analizadas por esta regla y se deben analizar aspectos como el mercado relevante, la naturaleza, el propósito y el efecto de la práctica para determinar si es o no anticompetitiva.

67 Laudo Arbitral de Andrés Pardo Vargas Contra World Management Advisors Ltda, Roberto Eduardo Hall Espinosa u Carlos Alberto Hall Espinosa. Bogotá Julio 26 de 2013. pp. $125-161$. 
empresa, donde la información reservada constituye un elemento esencial para subsistir y crecer, por lo que es esencial para todo empresario garantizar la protección de su información técnica y comercial. ${ }^{68}$ Debido a lo anterior el legislador ha considerado que deba ser protegido penalmente estableciendo mediante diferentes tipos penales su protección. Donde el bien jurídico que se protege es el patrimonio económico.

Es protegido por el artículo 18 de la ley 1474 de 2011 modifico el artículo 258 del código penal el cual quedo así:

"ARTICULO 258. Utilización indebida de información privilegiada. El que como empleado, asesor, directivo o miembro de una junta u órgano de administración de cualquier entidad privada, con el fin de obtener provecho para sí o para un tercero, baga uso indebido de información que baya conocido por razón o con ocasión de su cargo o función y que no sea objeto de conocimiento público, incurrirá en pena de prisión de uno (1) a tres (3) años y multa de cinco (5) a cincuenta (50) salarios mínimos legales mensuales vigentes.

En la misma pena incurrirá el que utilice información conocida por razón de su profesión u oficio, para obtener para sí o para un tercero, provecho mediante la negociación de determinada acción, valor o instrumento registrado en el Registro Nacional de Valores, siempre que dicha información no sea de conocimiento público."

Con este tipo penal se pretende evitar que el particular utilice indebidamente, con el fin de obtener provecho para sí o para un tercero, la información que llegue a su conocimiento en razón o con ocasión de sus funciones. Esa información no debe ser objeto de conocimiento público.

De acuerdo al Doctor Iván González Amado ${ }^{69}$ el sujeto activo del delito de acuerdo a los antecedentes de esta norma era constituido exclusivamente por el servidor público pero posteriormente en el trámite legislativo se incluyó al particular como sujeto activo pero solo al que desempeñara en la entidad privada un cargo de directivo o miembro de una junta directiva en una entidad que administrara recursos parafiscales, pero posteriormente en la gaceta judicial que contenía el acto de conciliación desapareció del texto del articulado la expresión "que administre bienes parafiscales" y además se incluyó la palabra empleado por lo que el sujeto activo paso a ser indeterminado. Lo anterior tuvo como consecuencia que el sujeto activo pueda ser cualquier persona que se encuentre vinculada a la entidad y que por su función conociera cierta información, por lo que para el autor se salvaguarda es el interés de las empresas en conservar para si una información por lo que para él no debería establecer un

68 RUIZ, Carmen. Derecho de la competencia y protección penal de la información. En: XXXII Jornadas Internacionales de Derecho Penal. Derecho Penal Económico y de la Empresa. Universidad Externado de Colombia. 2010. p. 133.

69 En su artículo "Utilización Indebida de Información Privilegiada", en: Revista Derecho Penal Y Criminología, Vol. 18, No. 59, Mayo- Agosto 1996, Bogotá, pp. 91-119. 
tipo de manera abierta ya que conlleva a que se sancionen comportamientos claramente inocuos para para los bienes jurídicos.

La conducta en el delito está dada por la expresión hacer uso que consiste en emplear la información obtenida por el sujeto activo de la conducta. El uso indebido se da cuando se emplea de manera directa la información privilegiada o simplemente se divulga dándola a conocer a un tercero. ${ }^{70}$ Este tipo contiene un elemento subjetivo ya que el sujeto activo debe tener el propósito de obtener un provecho para sí o para otro, de lo contrario la conducta seria atípica, no es necesario que lo obtenga sino que puede tener simplemente la expectativa de que sea así. ${ }^{71}$

Para el doctor Suarez, el sujeto pasivo no solamente son personas jurídicas sino que se debe entender que también se pueden cometer estos delitos en contra de personas naturales titulares del derecho de dominio sobre la información privilegiada. ${ }^{72}$

Este delito admite la modalidad en tentativa, en este caso el sujeto activo todavía no la ha divulgado o ha hecho uso de ella, pero tiene la intención de hacerlo. También puede existir concurso entre este delito y el tipo de corrupción privada (inciso segundo artículo 250A Código Penal) este concurso seria efectivo en el momento en que se solicita una dadiva por parte de la persona que esté usando la información de forma indebida al tercero al cual se la va a transmitir. ${ }^{73}$

Dentro de los delitos contra el orden económico y social también se da una protección al secreto industrial y se establece que:

"Artículo 308. Violación de reserva industrial o comercial. El que emplee, revele o divulgue descubrimiento, invención científica, proceso o aplicación industrial o comercial, llegados a su conocimiento por razón de su cargo, oficio o profesión y que deban permanecer en reserva, incurrirá en prisión de dos (2) a cinco (5) años y multa de veinte a dos mil (2.000) salarios mínimos legales mensuales vigentes.

En la misma pena incurrirá el que indebidamente conozca, copie u obtenga secreto relacionado con descubrimiento, invención científica, proceso o aplicación industrial o comercial.

La pena será de tres (3) a siete (7) años de prisión y multa de cien (100) a tres mil (3.000) salarios mínimos legales mensuales vigentes, si se obtiene provecho propio o de tercero."

70 SÚAREZ, Alberto. Delitos contra el Patrimonio Económico, Universidad Externado de Colombia, 2013. p. 463.

71 Ibíd. p. 467.

72 Ibíd. p. 466

73 Ibíd. pp. 467-468 
En este caso se puede concluir que no todos los secretos del empresario son protegidos penalmente, sino solo los que se puedan considerar como industriales. Por lo que se excluye la protección a los secretos de negocios, relacionados con listas de clientes, condiciones ventajosas dadas por los proveedores, archivos de personal entre otros. ${ }^{74}$

Es un tipo de peligro, ay que con la sola puesta en peligro de que desaparezca el secreto se sanciona, sin importar si se obtiene o no derecho.

En este artículo se encuentran dos modalidades:

a. Violación de la reserva industrial o comercial propiamente dicha: se configura cuando la persona que legítimamente conoce el objeto del secreto, lo posee con motivo de su trabajo, profesión, relación de negocios o del otorgamiento de una licencia para su uso, sin consentimiento de la persona que guarde el secreto, emplea, revela o divulga el secreto con el propósito de obtener un beneficio económico o con el fin de causar un perjuicio a la persona que guardaba el secreto.

b. Espionaje industrial: en este caso la persona accede de manera indebida al secreto, sin el consentimiento del titular.

\subsection{Aproximación del autor al problema}

El conflicto de intereses que puede surgir en cabeza del administrador merece un mayor desarrollo por parte de la legislación en Colombia debido a que en la actualidad las grandes sociedades delegan la administración de las mismas a terceros profesionales debido a que se preocupan más por las utilidades que por el gobierno de la misma, por lo que los administradores podría tomar provecho de esto y realizar actos que puedan llegar a generarle un perjuicio a la sociedad sin que los socios tengan conocimiento, inclusive puede llegar a la liquidación de la sociedad. Por lo que es necesario que el legislador les atribuya una mayor responsabilidad a los administradores frente a los actos que realicen y por eso se han establecido obligaciones y deberes para la protección de los socios y de la sociedad especialmente.

El deber de lealtad tiene poco desarrollo dentro de la ley, por lo que es necesario acudir a la doctrina y ver que se entiende por lealtad, y como el conflicto de intereses puede violar este deber mediante diferentes actos que la legislación no ha regulado de manera exhaustiva sino que el legislador se conformó con la simple enunciación de algunos. Inclusive el concepto sobre conflicto de intereses no se encuentra en la legislación colombiana.

Debido a la importancia que tiene la información en la actualidad y como esta es ahora considerada como el bien más importante de la sociedad, su

74 PACHON, Manuel. Protección de los Derechos de la Propiedad Industrial, Temis, Bogotá, 1986. p. 96. 
falta de protección puede llevar a que una sociedad pierda su valor, a actos anticompetitivos que perjudiquen el mercado e incluso a conductas penales que afecten a la economía.

Es necesario que haya un mayor desarrollo partiendo de lo más mínimo, estableciendo los elementos para considerar que es información privilegiada, cuáles son sus características, entre otros, para así llegar a establecer en que situaciones, no tan superficiales como las de la circular 6 de 2008, se debe considerar que se usó indebidamente la información.

Debido a lo anterior fue necesaria la protección se ha dado en ámbitos diferentes del derecho societario, como el derecho penal para sancionar penalmente la conducta, pero no porque se infrinja las obligaciones que tiene el administrador con la sociedad sino porque se protege es el patrimonio económico. Se ha dado también la protección en el ámbito de la propiedad industrial y de la competencia cuyo fin es la protección del secreto empresarial para evitar los actos anticompetitivos que afecten el mercado. Por lo que se podría afirmar que se protege en una mayor medida la información de la sociedad en otros ámbitos que en el propio derecho societario.

En otras legislaciones como la española se ha tenido un mayor desarrollo respecto a los conflictos de interés y su tipología, estableciendo leyes especiales para lograr una protección de los intereses de la sociedad y de sus asociados. En el caso del common law ha habido un mayor desarrollo pero respecto de los actos denominados "insider trading".

\section{CONCLUSIONES}

El deber de lealtad que deben tener los administradores con la sociedad es la base que permite establecer que los administradores deban abstenerse de realizar actos en los cuales exista un conflicto de intereses.

Dentro de la legislación colombiana se encuentra establecida la tipología de los diferentes conflictos que se pueden radicar en cabeza del administrador pero no se tiene un desarrollo legal sobre sus contenidos.

Debido al desarrollo de la sociedad, actualmente la información es uno de los activos más importantes de una sociedad, lo que llevo a que fuera protegida legalmente frente a la mala utilización que se le puede dar por parte de los administradores.

En la legislación no hay un desarrollo sobre la información privilegiada, sino que es una entidad administrativa la que desarrolla las características que debe tener la información para considerarse privilegiada y merezca protección.

La información de una sociedad tiene tal importancia que ha sido protegida por el derecho internacional mediante acuerdos internacionales y por la comunidad andina de naciones los cuales han sido plasmados dentro de nuestra legislación estableciendo prohibiciones a quien tiene acceso a la información 
para poder protegerla y evitar que su uso indebido le genere consecuencias a la sociedad.

En el derecho de la competencia se han utilizado para su protección la cláusula de no competencia, como algo accesorio al contrato para lograr la protección de la información.

En el derecho comparado se considera importante la protección de la información, por lo que en el common law se establece la responsabilidad de quien realiza transacciones denominadas insider traiding. En el derecho español hay un mayor desarrollo de los diferentes actos mediante los cuales el administrador puede vulnerar el deber de lealtad encontrándose en una situación de conflicto de intereses.

\section{BIBLIOGRAFÍA}

ALMONACID SIERRA, Juan Jorge; GARCÍA LOZADA, Nelson Gerardo. Derecho de la Competencia, Legis, 1998.

BARRIENTOS RESTREPO, Ana Lucia. Administradores, información confidencial y propiedad accionaria. En: Revista de Derecho y ciencias políticas, edición universidad pontificia bolivariana, No 99, 1998, Medellín.

CASTRO GARCÍA, Juan David. La Propiedad Industrial, Universidad Externado de Colombia, 2009.

Circular Externa de la Superintendencia de Sociedades No. 06 de 2008.

CÓRDOBA, Pablo Andrés. El derecho de las sociedades y el gobierno de la sociedad anónima: el interés social, órganos, accionistas y administradores. Primera Edición, Universidad Externado de Colombia, Bogotá, 2014.

CUIF, Pierre-Francois. El conflicto de intereses: ensayo sobre la determinación de un principio jurídico en derecho privado, Revista de Derecho Privado, Nos. 12 y 13, Diciembre de 2007, Bogotá.

DOBSON, Juan I. Interés societario. Ed. Astrea, Argentina, 2010.

GAITAN, Nicolás. La Autocontratación En El Derecho De Sociedades Colombiano: Deber De Lealtad, Interés Social Y Vínculo Jurídico Administrador-Sociedad. En: Revista e-mercatoria Vol. 12, No. 2 (jul-dic. 2013).

GALAN CORONA, Eduardo. Tipos de Deslealtad en Materia de Secretos Empresariales. EN: Estudios de derecho mercantil en homenaje al profesor José María Muñoz Planas. 2011. 
GIRALDO MORENO, Carlos. La Información Privilegiada de la Empresa su Tratamiento en Colombia y en el Derecho Comercial Comparado, en: La Contratación Mercantil y otros aspectos comerciales, Colegio abogados de Medellín, biblioteca jurídica Dike.

GONZALEZ AMADO, Iván. Utilización Indebida de Información Privilegiada, Revista Derecho Penal Y Criminología, Vol. 18, No. 59, Mayo-Agosto 1996, Bogotá, pp. 91-119.

Laudo Arbitral de Andrés Pardo Vargas Contra World Management Advisors Ltda., Roberto Eduardo Hall Espinosa y Carlos Alberto Hall Espinosa. Bogotá Julio 26 de 2013.

LLEBOT MAJO, J.O., Deberes y responsabilidad de los administradores, en La Responsabilidad de los Administradores (dir.:Rojo, A. Y Beltrán, E.), Tirant lo Blanch, Valencia, 2011.

PACHON, Manuel. Protección de los Derechos de la Propiedad Industrial, Temis, Bogotá, 1986.

RAMIREZ, Mónica. COMPETENCIA DESLEAL por violación al secreto empresarial, tesis de grado, Bogotá D.C 2001.

REYES VILLAMIZAR, Francisco. Derecho Societario en los Estados Unidos: introducción comparada. 2. ${ }^{a}$ ed., Editorial Legis, Bogotá, 2005.

REYES VILLAMIZAR, Francisco. SAS: La Sociedad Por Acciones Simplificada. 2da edición. Editorial Legis. 2012.

RIBAS FERRER, Vincec. El Deber de Lealtad del Administrador de Sociedades. La Ley, Madrid, 2010.

RUIZ, Carmen. Derecho de la competencia y protección penal de la información. En: XXXII Jornadas Internacionales de Derecho Penal. Derecho Penal Económico y de la Empresa. Universidad Externado de Colombia. 2010.

SABOGAL, Luis Fernando. Los Conflictos De Interés De Los Administradores Bajo El Nuevo Paradigma De La Transparencia En El Gobierno Societario. En: Revista e-mercatoria Vol. 12, No. 1 (enero-junio 2013)

SANCHEZ CALERO, Fernando. Los administradores en las sociedades de capital. 2. ${ }^{\text {a }}$ ed., Thomson-Civitas, 2007.

Sentencia Superintendencia de Sociedades. Partes: SAC Estructuras Metálicas S.A. contra Praxedis José Daniel Correa Senior, Santiago Francisco Correa Laverde y Gloria Estella Gallo Pérez. 
SERRANO CAÑAS. José Manuel. El conflicto de intereses en la administración de sociedades mercantiles, Bolonia, Publicaciones del Real Colegio de España, 2008.

SÚAREZ, Alberto. Delitos contra el Patrimonio Económico, Universidad Externado de Colombia, 2013.

VICENT CHULIA, Francisco. Grupos de sociedades y conflictos de intereses. En: AA.VV. Estudios de Derecho Mercantil en homenaje al Profesor José María Muñoz Planas. Ed. Civitas, España. 